\title{
Article \\ Phosphoinositide 3-Kinase (PI3K) Reactive Oxygen Species (ROS)-Activated Prodrug in Combination with Anthracycline Impairs PI3K Signaling, Increases DNA Damage Response and Reduces Breast Cancer Cell Growth
}

\author{
Rosalin Mishra ${ }^{1}{ }^{(D}$, Long Yuan ${ }^{1,+}$, Hima Patel ${ }^{1,+}$, Aniruddha S. Karve ${ }^{1}\left(\mathbb{D}\right.$, Haizhou Zhu ${ }^{2}$, Aaron White ${ }^{1}(\mathbb{D}$, \\ Samar Alanazi ${ }^{1}$, Pankaj Desai ${ }^{1}$, Edward J. Merino ${ }^{2}$ and Joan T. Garrett ${ }^{1, *}$ \\ 1 Department of Pharmaceutical Sciences, College of Pharmacy, University of Cincinnati, \\ Cincinnati, OH 45267-0514, USA; mishrarn@ucmail.uc.edu (R.M.); yuanlg@mail.uc.edu (L.Y.); \\ patel2h2@mail.uc.edu (H.P.); karveas@mail.uc.edu (A.S.K.); white3ai@mail.uc.edu (A.W.); \\ alanazsa@mail.uc.edu (S.A.); desaipb@ucmail.uc.edu (P.D.) \\ 2 Department of Chemistry, University of Cincinnati, Cincinnati, OH 45267-0514, USA; \\ zhuhz@mail.uc.edu (H.Z.); merinoed@ucmail.uc.edu (E.J.M.) \\ * Correspondence: joan.garrett@uc.edu; Tel.: +1-513-558-0741; Fax: +1-513-558-4372 \\ + These authors contributed equally.
}

check for updates

Citation: Mishra, R.; Yuan, L.; Patel, H.; Karve, A.S.; Zhu, H.; White, A.; Alanazi, S.; Desai, P.; Merino, E.J.; Garrett, J.T. Phosphoinositide 3-Kinase (PI3K) Reactive Oxygen Species (ROS)-Activated Prodrug in Combination with Anthracycline Impairs PI3K Signaling, Increases DNA Damage Response and Reduces Breast Cancer Cell Growth. Int. J. Mol. Sci. 2021, 22, 2088. https:// doi.org/10.3390/ijms22042088

Academic Editor: Giovanni Natile

Received: 12 January 2021

Accepted: 15 February 2021

Published: 19 February 2021

Publisher's Note: MDPI stays neutral with regard to jurisdictional claims in published maps and institutional affiliations.

Copyright: () 2021 by the authors. Licensee MDPI, Basel, Switzerland. This article is an open access article distributed under the terms and conditions of the Creative Commons Attribution (CC BY) license (https:// creativecommons.org/licenses/by/ $4.0 /)$.

\begin{abstract}
RIDR-PI-103 is a novel reactive oxygen species (ROS)-induced drug release prodrug with a self-cyclizing moiety linked to a pan-PI3K inhibitor (PI-103). Under high ROS, PI-103 is released in a controlled manner to inhibit PI3K. The efficacy and bioavailability of RIDR-PI-103 in breast cancer remains unexplored. Cell viability of RIDR-PI-103 was assessed on breast cancer cells (MDAMB-231, MDA-MB-361 and MDA-MB-453), non-tumorigenic MCF10A and fibroblasts. Matrigel colony formation, cell proliferation and migration assays examined the migratory properties of breast cancers upon treatment with RIDR-PI-103 and doxorubicin. Western blots determined the effect of doxorubicin \pm RIDR-PI-103 on AKT activation and DNA damage response. Pharmacokinetic (PK) studies using C57BL/6J mice determined systemic exposure (plasma concentrations and overall area under the curve) and $\mathrm{T}_{1 / 2}$ of RIDR-PI-103. MDA-MB-453, MDA-MB-231 and MDA-MB-361 cells were sensitive to RIDR-PI-103 vs. MCF10A and normal fibroblast. Combination of doxorubicin and RIDRPI-103 suppressed cancer cell growth and proliferation. Doxorubicin with RIDR-PI-103 inhibited p-AktS473, upregulated p-CHK1/2 and p-P53. PK studies showed that $200 \mathrm{ng} / \mathrm{mL}(0.43 \mu \mathrm{M})$ RIDRPI-103 is achievable in mice plasma with an initial dose of $20 \mathrm{mg} / \mathrm{kg}$ and a $10 \mathrm{~h} \mathrm{~T} 1 / 2$. (4) The prodrug RIDR-PI-103 could be a potential therapeutic for treatment of breast cancer patients.
\end{abstract}

Keywords: breast cancer; reactive oxygen species; RIDR-PI-103; doxorubicin

\section{Introduction}

The phosphatidylinositol-3 kinase (PI3K) is a family of lipid kinases. Class IA PI3Ks are heterodimeric proteins with a p110 catalytic subunit and a p85 regulatory subunit and are involved in carcinogenesis. Within class IA, the genes PIK3CA, PIK3CB, and PI3KCD encode the homologous $\mathrm{p} 110 \alpha, \mathrm{p} 110 \beta$, and $\mathrm{p} 110 \delta$ isozymes respectively. PI3K is activated upstream by the binding of a ligand to its cognate receptor tyrosine kinase (RTK), which include members of the human epidermal growth factor receptor (HER) family, and insulinlike growth factor 1 (IGF-1) receptor, among others [1,2]. PI3K phosphorylates phosphatidylinositol 4,5-bisphosphate (PIP2) to phosphatidylinositol 3,4,5-triphosphate (PIP3), which in turn leads to phosphorylation of Protein kinase $\mathrm{B},(\mathrm{AKT})$, a serine/threonine kinase [3]. The PI3K pathway is hyper-activated in $>60 \%$ of clinical breast cancers due to aberrations in genes encoding HER2, PTEN, PIK3CA, or AKT1-3 [4-6].

Targeting the PI3K pathway with small molecular weight kinase inhibitors of PI3K, AKT, mTOR, HER2, or anti-HER2 antibodies has improved the outcome for many women 
with PI3K-activated breast cancer because the PI3K/mTOR pathway controls oncogenic processes such as tumor cell survival, motility, and invasion. Unfortunately, most cancers eventually acquire resistance to current PI3K or mTOR inhibitors demonstrating that improved therapeutic strategies are required. Further, drugs targeting PI3K or mTOR catalytic activity are toxic, due to the physiological roles of PI3K/mTOR signaling in basic cellular processes in tissues throughout the body, including protein translation, intracellular trafficking, autophagy, and metabolism. The genes encoding most glycolytic enzymes are under dominant transcriptional control by PI3K/AKT and thus hyperglycemia is one of the most common side-effects with PI3K pathway inhibitors [7]. Alpelisib, a PI3K $\alpha$ specific inhibitor, in combination with fulvestrant prolonged progression-free survival among patients with PIK3CA-mutated, hormone receptor (HR)-positive, HER2-negative advanced breast cancer who had received endocrine therapy previously [8]. Alpelisib recently received Food and Drug Administration (FDA) approval for this patient population [9]. Patients receiving alpelisib had an improved progression-free survival compared with fulvestrant alone by about 5 months and were at high risk of hyperglycemia-related adverse events. This modest benefit accompanied with significant tolerability challenges underscores the urgent need to identify potent, safe and tolerable PI3K inhibitors for breast cancer patients.

Elevated levels of reactive oxygen species (ROS) deregulated redox signaling and change in redox balance are frequent hallmarks of cancer progression [10]. ROS are highly reactive metabolites of oxygen including superoxide, hydrogen peroxide, hydroxyl radical, and hypochlorous acid. Cancer cells show persistent metabolic oxidative stress compared to normal cells, related to mitochondrial dysfunction. In addition, estrogens and metabolites of estrogen produce ROS in cancer cells [11]. We have developed a novel technology, called ROS-induced drug release (RIDR) that prevents inhibition of PI3K by a parent molecule until a high ROS environment is induced. The high ROS level leads to a chemical reaction that releases the known PI3K inhibitor to improve specificity of cancer cell activity [12,13]. We have focused on a small molecule, PI-103 [14-16] that produces tumor reduction in models of breast [17], lung cancer [18,19], and skin cancer. We observed increased selectivity of RIDR-PI-103 in the human acute myeloid leukemia cell line Kasumi-1 over normal cells, but no bioavailability data was performed in our previous study [20].

Anthracyclines, including doxorubicin, are a class of chemotherapeutics which have been FDA approved since the 1970s. Doxorubicin is a highly effective, first line chemotherapeutic agent used in the management of hematological and solid tumors and is costeffective. Doxorubicin exerts its cytotoxic effect by intercalating DNA. Doxorubicin binds to DNA and topoisomerase 2 isoenzymes forming a ternary Top2-doxorubicin-DNA complex, which causes double-stranded DNA breaks [21]. Doxorubicin induces oxidative stress in cardiomyocytes [22,23] and can cause cardiomyopathy [24].

Our study indicates that low concentration of doxorubicin in combination with RIDRPI-103 suppresses cancer cell growth and proliferation via inhibition of AKT signaling and induction of DNA damage response in breast cancer models.

\section{Results}

\subsection{RIDR-PI-103 Has Increased Specificity in Breast Cancer Cells over Fibroblast and MCF10A Cells}

We evaluated the toxicity effect of ROS-induced drug release 3-(4-morpholinopyrido$\left[3^{\prime}, 2^{\prime}: 4,5\right]$ furo[3,2-d]pyrimidin-2-yl)phenol (RIDR-PI-103) (described in [20]) on normal fibroblasts, normal mammary epithelial breast cells MCF10A and estrogen receptor positive (ER+) MDA-MB-361, triple negative breast cancer (TNBC) MDA-MB-231 and HER2+ MDAMB-453 breast cancer cell lines [25] using a $72 \mathrm{~h}$ 4,5-dimethylthiazol-2-yl)-2,5-diphenyltetrazolium bromide (MTT) cell proliferation assay. MDA-MB-453 cells contain the PIK3CA H1047R hot spot mutation and MDA-MB-361 contains PIK3CA E545K hot spot mutation [25]. We utilized MDA-MB-231 cells as these triple negative breast cancer (TNBC) cells have increased ROS compared to other breast cancer cells [26] and thus could have more activation of the ROS-activated scaffold drug. We found variable sensitivity of cells to RIDR-PI-103 (Figure 1). At concentrations of $50 \mu \mathrm{M}(\log 1.7 \mu \mathrm{M})$ or greater the three breast 
cancer cell lines showed growth inhibition to RIDR-PI-103, whereas normal fibroblasts or MCF10A cells did not respond appreciably to treatment (Figure 1). Dose response of PI-103 $(0-5 \mu \mathrm{M})$ in MCF10A, normal fibroblasts and breast cancer cells is provided in Figure S1. Comparison of IC $_{50}$ values of PI-103 and RIDR-PI-103 is tabulated in Table S1.

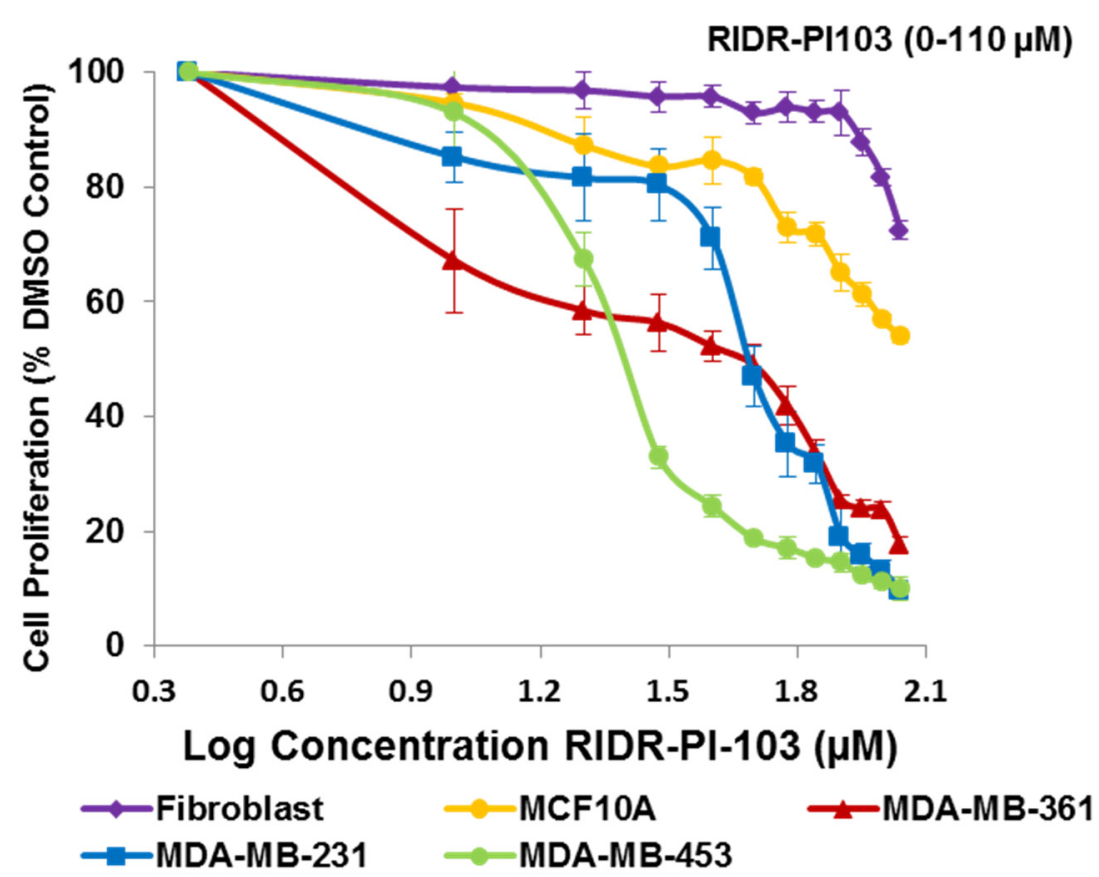

Figure 1. Dose response of RIDR-PI-103 in MCF10A, normal fibroblasts and breast cancer cells. NH fibroblasts, MCF10A, MDA-MB-231, MDA-MB-361 and MDA-MB-453 cells were plated in triplicate in 96 well plates and treated with RIDR-PI-103 $(0-110 \mu \mathrm{M})$ for $72 \mathrm{~h}$. The data was analyzed and presented using GraphPad Prism v7 $(n=3$ independent experiments performed in triplicate \pm SEM). IC50 values determined using graph pad prism as: Fibroblasts $=$ N.D.; $\mathrm{MCF} 10 \mathrm{~A}=78.6 \mu \mathrm{M}$; MDA-MB-231 $=47.3 \mu \mathrm{M}$, MDA-MB-361 $=43.01 \mu \mathrm{M}$ and MDA-MB-453 $=49.05 \mu \mathrm{M}$.

\subsection{Doxorubicin Induces ROS and Combination of RIDR-PI-103 and Doxorubicin Inhibits Breast Cancer Cell Viability}

ROS levels were measured in MCF10A, MDA-MB-231, MDA-MB-361 and MDA-MB453 cells with or without 30 min of doxorubicin $(125 \mathrm{nM})$ treatment using $2^{\prime}, 7^{\prime}$ dichlorofluorescin diacetate (DCFDA) assay. The data indicated that MDA-MB-231 cells have the highest endogenous ROS versus MDA-MB-361, MDA-MB-453 and MCF10A cells. MCF10A cells have the lowest ROS levels compared to the three cancer cell lines. Doxorubicin induced ROS in all treatment groups (Figure 2A). In addition, we evaluated endogenous levels of antioxidants such as catalase, SOD1, SOD2, PRDX1 and GSR in fibroblast, MDAMB-231, MDA-MB-361 and MDA-MB-453 cells. The data indicated that catalase expression was lower in all three breast cancer cell lines versus fibroblast. SOD1 levels are elevated in all three breast cancer cell lines versus fibroblast. There was variation in expression of SOD2, PRDX1 and GSR that didn't correlate across the cancer cell lines and fibroblast (Figure S2). We next evaluated the combination of RIDR-PI-103 and doxorubicin in MDA-MB-231, MDA-MB-361 and MDA-MB-453 cell lines. We used serial concentrations of doxorubicin in combination with RIDR-PI-103 $(10-30 \mu \mathrm{M})$ based on the $\mathrm{IC}_{50}$ values of doxorubicin in different cancer cell lines. We found that 10, 15 and $30 \mu \mathrm{M}$ RIDR-PI-103 enhances the cytotoxicity of the anthracycline doxorubicin in MDA-MB-231, MDA-MB-361 and MDA-MB-453 (Figure 2B-D). We further assessed the effect of the ROS scavenger, N-Acetyl Cysteine (NAC) alone or with RIDR-PI-103 +/- doxorubicin in MDA-MB-231 and MDA-MB-453 cells. We observed that NAC rescued the antiproliferative effects of RIDR-PI-103 and doxorubicin in MDA-MB-231 cells (Figure S3A) but not in MDA-MB-453 cells (Figure S3B). Our data indicate that MDA-MB-231 cells contain more endogenous ROS 
than MDA-MB-453 (Figure 2A). We speculate that with increased ROS, MDA-MB-231 cells may be more sensitive to treatment with the ROS scavenger NAC, allowing for rescue of treatment with RIDR-PI-103 and doxorubicin. We also analyzed the effect of docetaxel [27], part of the taxane class that act as anti-microtubule agents, in combination with RIDR-PI103. The data indicated that docetaxel was less effective in combination with RIDR-PI-103 to suppress breast cancer cell growth (Figure S4A-C). IC50 values of DOXO, DOXO $\pm 10 \mu \mathrm{M}$ RIDR, DOXO $\pm 15 \mu \mathrm{M}$ RIDR and DOXO $\pm 30 \mu \mathrm{M}$ RIDR in MDA-MB-231, MDA-MB-361 and MDA-MB-453 cell lines are provided in Table S2. Notably, in MDA-MB-231 cells the $\mathrm{IC}_{50}$ value was reduced by more than one half comparing doxorubicin and RIDR-PI-103 combination versus doxorubicin alone (Table S2).
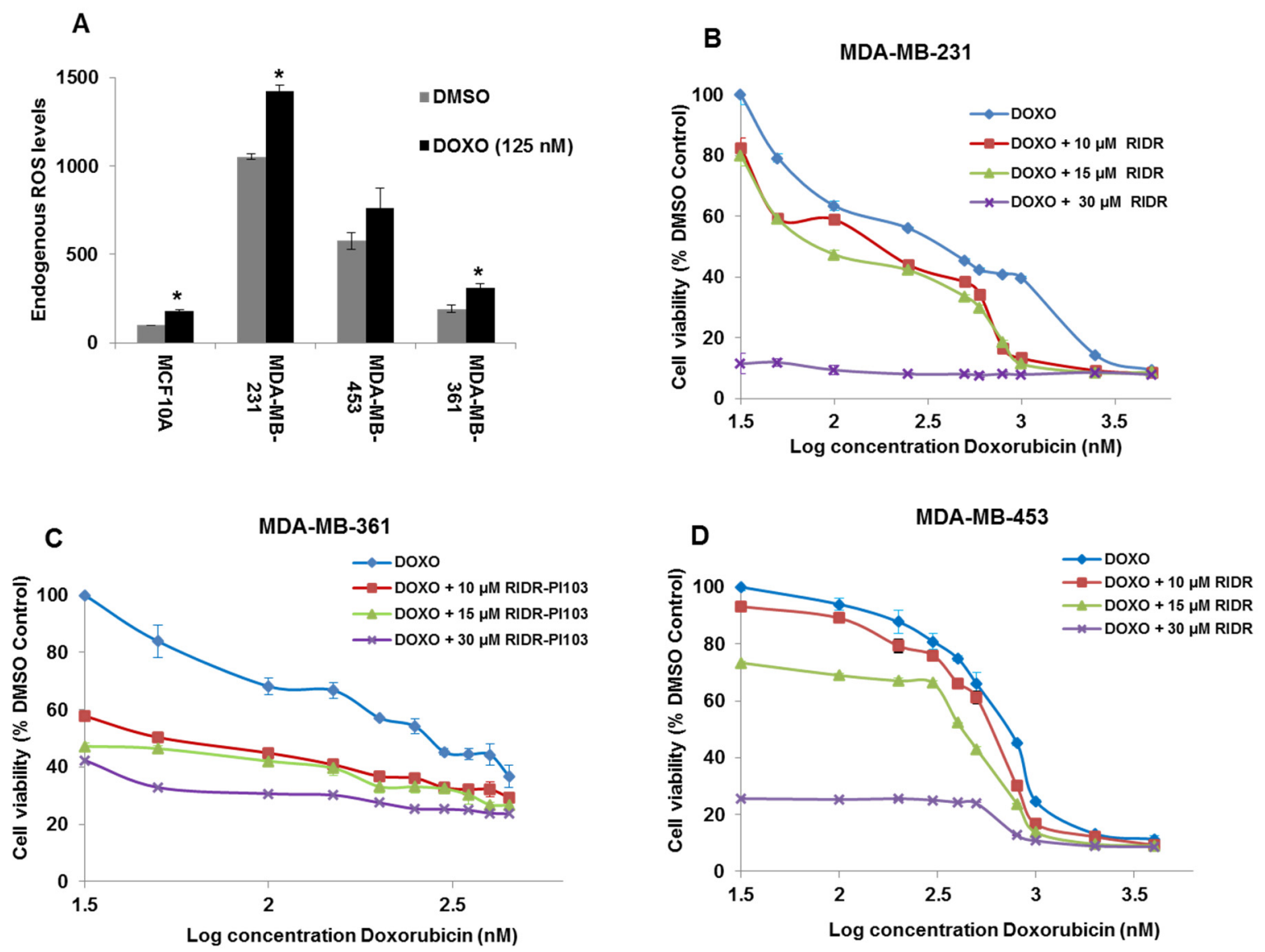

Figure 2. Doxorubicin induces ROS and combination of RIDR-PI-103 and Doxorubicin inhibit breast cancer cell viability. (A) Reactive oxygen species (ROS) levels were measured by DCFDA assay where MCF10A, MDA-MB-231, MDA-MB-361 and MDA-MB-453 cells were treated with or without $125 \mathrm{nM}$ doxorubicin (DOXO) for 30 min. Dimethyl sulfoxide (DMSO) was used as vehicle control. Results are represented as mean \pm SEM from 3 biological triplicates and represented graphically. * indicates $p<0.05$ compared to DMSO treatment. (B) MDA-MB-231 cells $\left(2 \times 10^{4}\right.$ cells/well) were seeded in 96 well plates in triplicate and treated with a serial concentration of doxorubicin (DOXO) in presence of $10 \mu \mathrm{M}, 15 \mu \mathrm{M}$ and $30 \mu \mathrm{M}$ RIDR-PI-103 (RIDR) for $72 \mathrm{~h}$. The concentration of doxorubicin used was 500-5000 nM for MDA-MB-231. (C) MDA-MB-361 cells $\left(2 \times 10^{4}\right.$ cells / well $)$ were seeded in 96 well plates in triplicate and treated with a serial concentration of doxorubicin (DOXO) in presence of $10 \mu \mathrm{M}, 15 \mu \mathrm{M}$ and $30 \mu \mathrm{M}$ RIDR-PI-103 (RIDR) for $72 \mathrm{~h}$. The concentration of doxorubicin used was 50-450 nM for MDA-MB-361. (D) MDA-MB-453 cells $\left(2 \times 10^{4}\right.$ cells/well) were seeded in 96 well plates in triplicate and treated with a serial concentration of doxorubicin (DOXO) in presence of $10 \mu \mathrm{M}, 15 \mu \mathrm{M}$ and $30 \mu \mathrm{M}$ RIDR-PI-103 (RIDR) for $72 \mathrm{~h}$. The concentration of doxorubicin used was 100-4000 nM for MDA-MB-453. All the cells were treated with MTT $(5 \mathrm{mg} / \mathrm{mL})$ for $4 \mathrm{~h}$ and absorbance read at $570 \mathrm{~nm}$ in a microtiter plate reader $(n=3$ independent experiments performed in triplicate \pm SEM). 


\subsection{Doxorubicin in Combination with RIDR-PI-103 Suppresses Breast Cancer Cell Proliferation}

We speculated that the combination of doxorubicin and RIDR-PI-103 could effectively inhibit breast cancer cell proliferation. Accordingly, MDA-MB-231, MDA-MB-361 and MDA-MB-453 cells were treated with doxorubicin $(125 \mathrm{nM})$ and RIDR-PI-103 $(10 \mu \mathrm{M})$ every alternative day and stained after 10-12 days using a two-dimensional crystal violet assay. The data indicated that the combination of doxorubicin and RIDR-PI-103 significantly reduced cancer cell proliferation versus DMSO or single agent doxorubicin or RIDR-PI-103 in all three cell lines (Figure 3A-C).

A
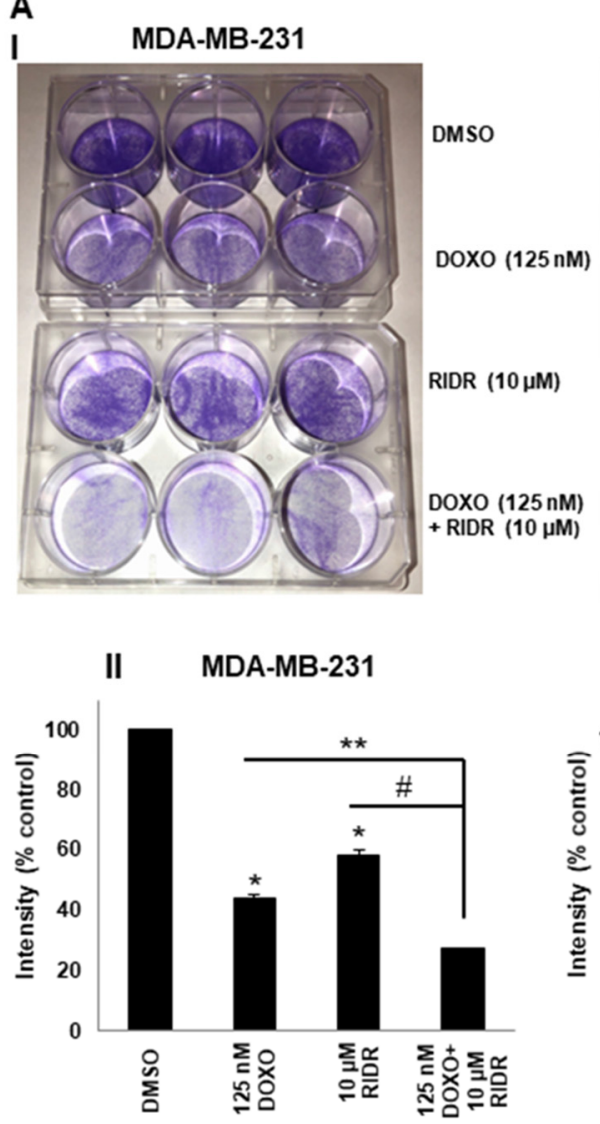

B
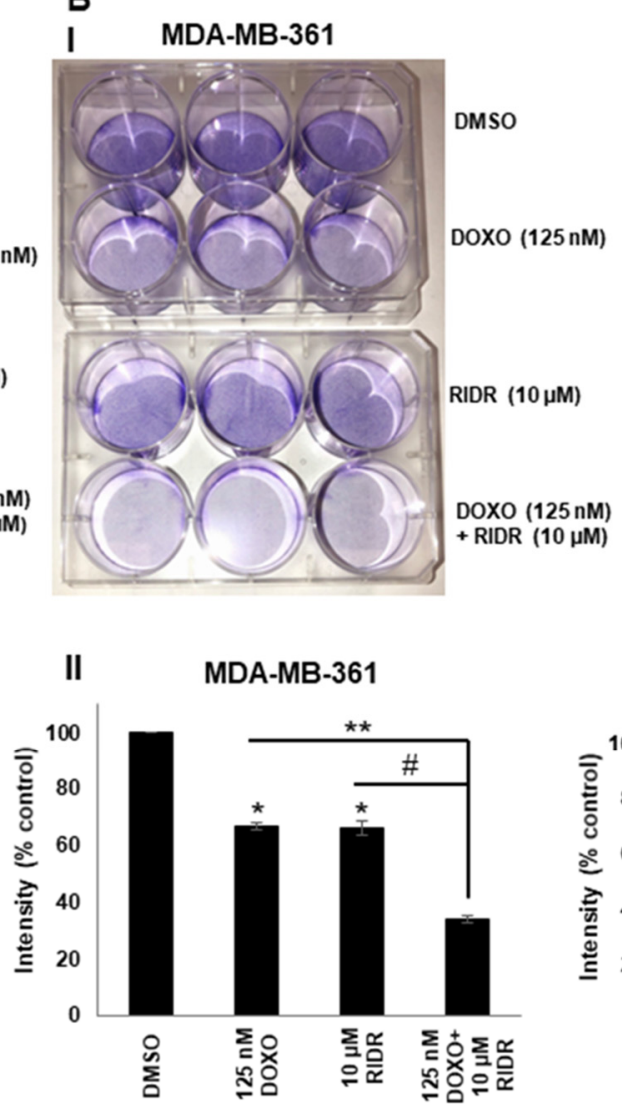

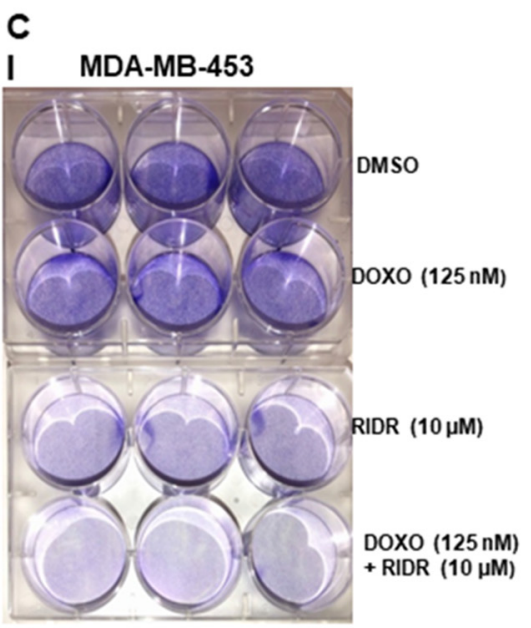

II MDA-MB-453

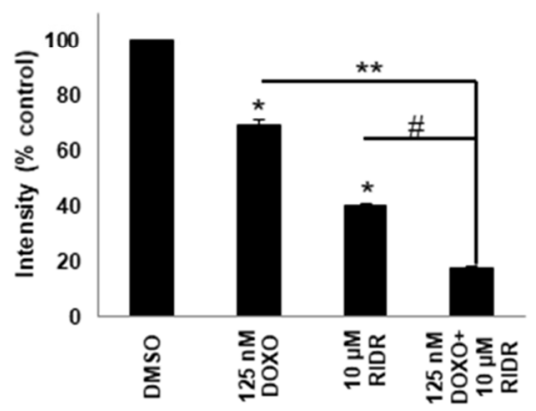

Figure 3. Combination of doxorubicin and RIDR-PI-103 inhibit breast cancer cell proliferation. (A) MDA-MB-231 cells $\left(5 \times 10^{4}\right.$ cells / well) were plated and treated with media containing vehicle (DMSO), doxorubicin (125 nM) or RIDR-PI-103 $(10 \mu \mathrm{M})$ and indicated combinations every second day and stained with crystal violet within 7-10 days (panel I). The intensities are represented as mean; Error bars: $\operatorname{SEM}\left(n=3\right.$ independent experiments performed in triplicate). ${ }^{*} p<0.05$ versus DMSO and $* * *, p<0.05$ versus individual treatment as indicated (panel II). (B) MDA-MB-361 cells $\left(5 \times 10^{4}\right.$ cells $/$ well) were plated and treated with media containing vehicle (DMSO), doxorubicin (125 nM) or RIDR-PI-103 (10 $\mu \mathrm{M})$ and indicated combinations every second day and stained with crystal violet within 7-10 days (panel I). The intensities are represented as mean; Error bars: SEM $\left(n=3\right.$ independent experiments performed in triplicate). ${ }^{*} p<0.05$ versus DMSO and ${ }^{* *}, p<0.05$ versus individual treatment as indicated (panel II). (C) MDA-MB-453 cells $\left(5 \times 10^{4}\right.$ cells/well) were plated and treated with media containing vehicle (DMSO), doxorubicin (125 nM) or RIDR-PI-103 (10 $\mu \mathrm{M})$ and indicated combinations every second day and stained with crystal violet within 7-10 days (panel I). The intensities are represented as mean; Error bars: SEM ( $n=3$ independent experiments performed in triplicate). ${ }^{*} p<0.05$ vs. DMSO and ${ }^{* *}{ }^{*} p<0.05$ versus individual treatment as indicated (panel II).

\subsection{Doxorubicin in Combination with RIDR-PI-103 Suppresses Matrigel Colony Formation}

Examination of cells grown on a basement membrane of matrigel indicated that combination doxorubicin (125 nM) and RIDR-PI-103 $(10 \mu \mathrm{M})$ inhibit colony formation better than either single agent. Our data showed that the combination of doxorubicin 
with RIDR-PI-103 significantly suppressed colony formation on matrigel compared to individual drugs or DMSO control in MDA-MB-231, MDA-MB-361 and MDA-MB-453 cells. MDA-MB-453 cells were most sensitive to the combination of doxorubicin and RIDR-PI-103 marked by significantly reduced colonies versus single agent RIDR-PI-103 or doxorubicin or DMSO. MDA-MB-231 cells displayed aggressive growth with vehicle treatment and had a statistically significant reduction in the colony formation with combination treatment versus either single agent treatment (Figure $4 \mathrm{~A}-\mathrm{C}$ ).

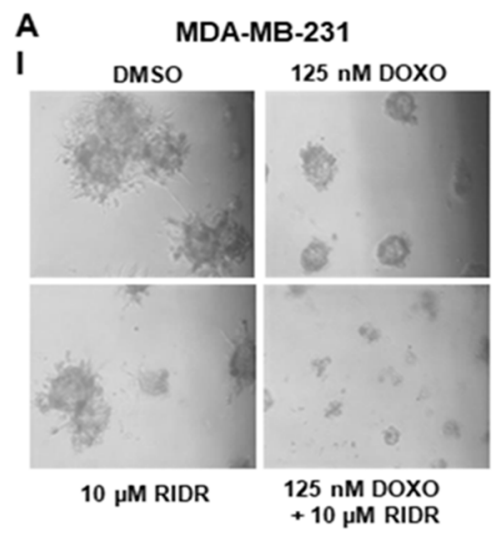

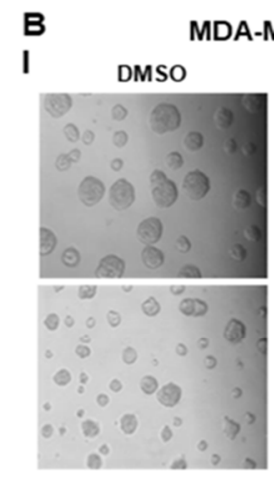

$10 \mu \mathrm{M}$ RIDR

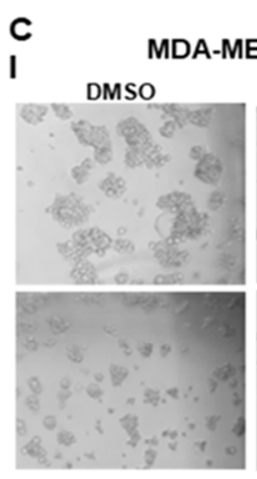

$10 \mu \mathrm{M}$ RIDR
$125 \mathrm{nM}$ DOXO

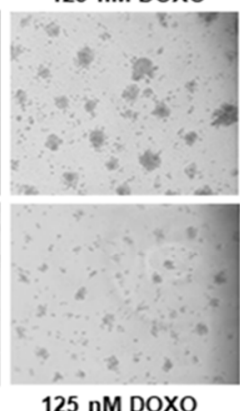

$+10 \mu \mathrm{M}$ RIDR

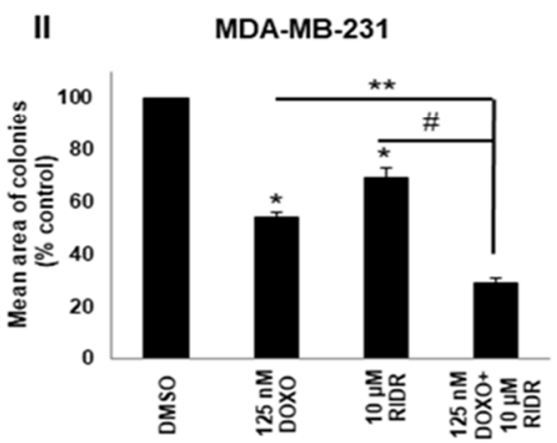

\section{II}

MDA-MB-361

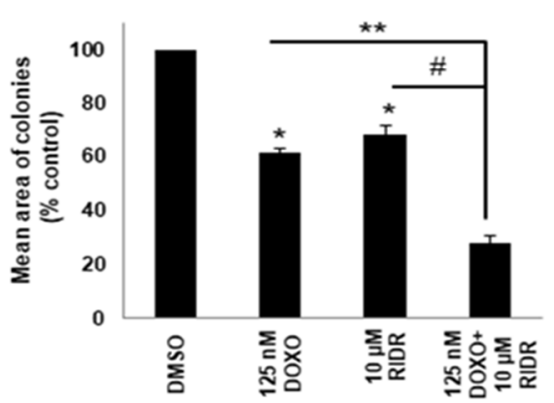

II

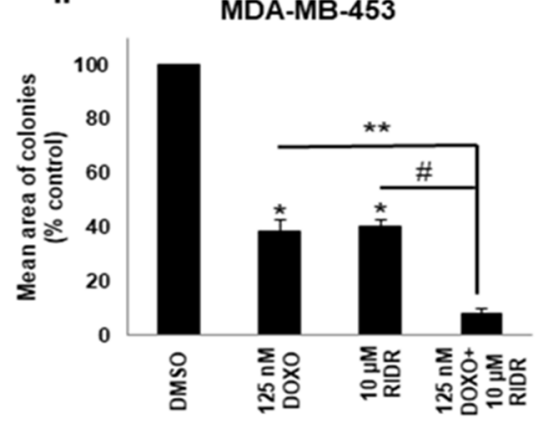

Figure 4. Doxorubicin and RIDR-PI-103 inhibit colony formation on matrigel. (A) MDA-MB-231 cells $\left(2 \times 10^{4}\right.$ cells $/$ well $)$ were seeded on a basement membrane of matrigel and treated with vehicle (DMSO), doxorubicin (125 nM), RIDR-PI-103 $(10 \mu \mathrm{M})$ or combination every second day. (B) MDA-MB-361 cells $\left(2 \times 10^{4}\right.$ cells / well) were seeded on a basement membrane of matrigel and treated with vehicle (DMSO), doxorubicin (125 nM), RIDR-PI-103 (10 $\mu \mathrm{M})$ or combination every second day. (C) Equal number of MDA-MB-453 cells were seeded on a basement membrane of matrigel and treated with vehicle (DMSO), doxorubicin (125 nM), RIDR-PI-103 (10 $\mu \mathrm{M})$ or combination every second day. Phase contrast images of acini for all cell lines were captured at $10 \times$ magnification (panel I) and the average size of each cellular structure was quantified and expressed as mean of areas \pm SEM, $\left(n=3\right.$ independent experiments performed in triplicate). ${ }^{*} p<0.05$ vs. DMSO and **\#, $p<0.01$ vs. respective treatment groups (panel II).

\subsection{Doxorubicin and RIDR-PI-103 Suppress Breast Cancer Cell Migration}

Transwell migration assay was performed to assess the effect of doxorubicin and RIDR-PI-103 on breast cancer cell migration. The data indicated that the combination of doxorubicin and RIDR-PI-103 inhibit breast cancer cell migration better compared to single agent doxorubicin, RIDR-PI-103 or DMSO control. Our cell migration data also showed that in all three breast cancer cell lines co-treatment of doxorubicin and RIDR-PI103 resulted in statistically significant reduction in migration compared to either single agent (Figure 5A-C). 
A
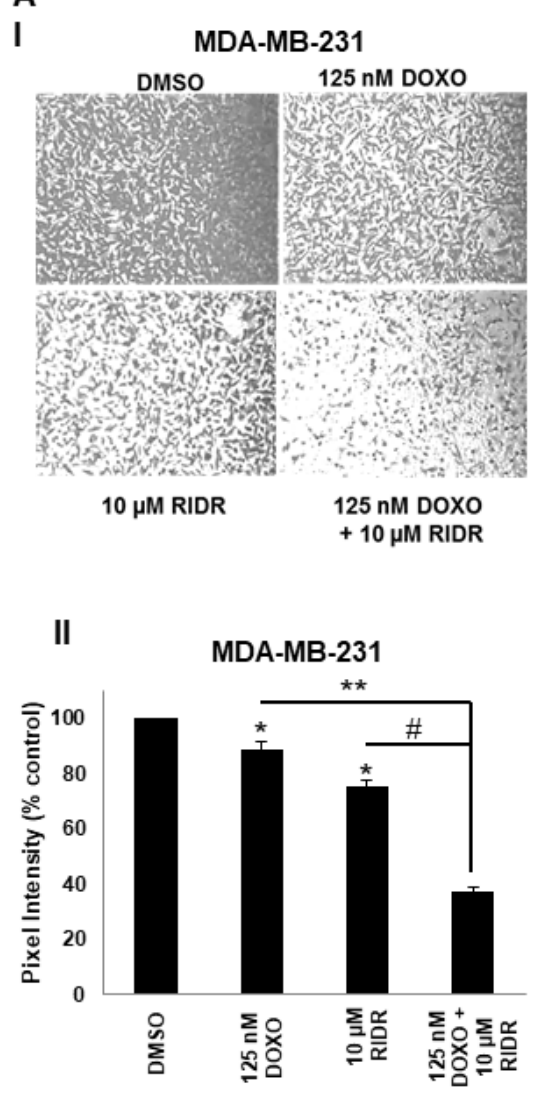

B
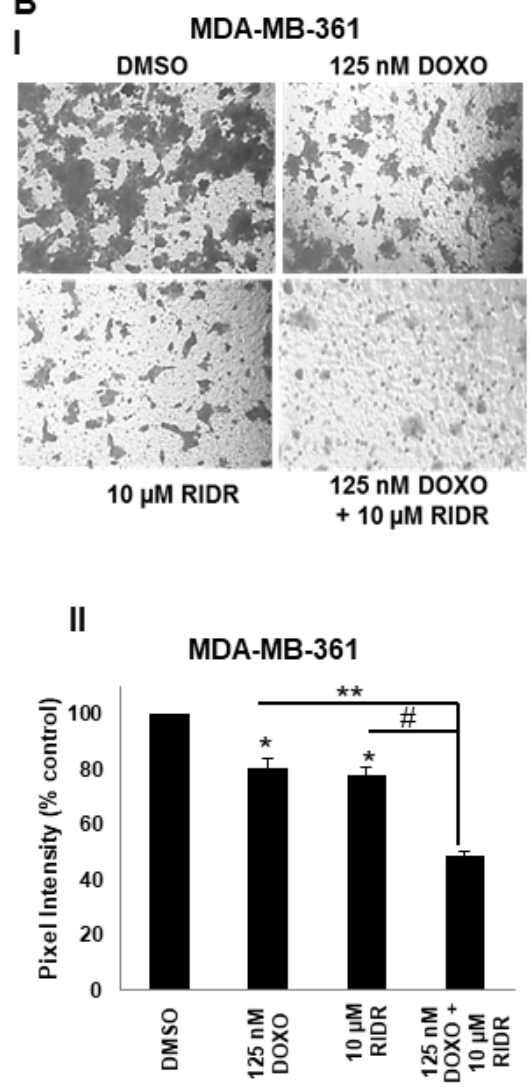
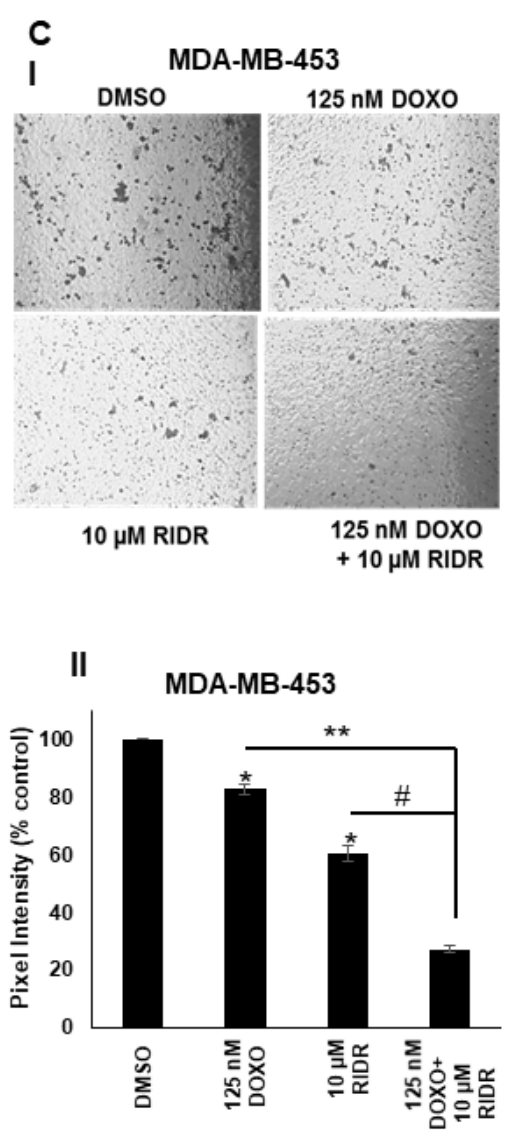

Figure 5. Doxorubicin and RIDR-PI-103 suppress breast cancer cell migration. (A) MDA-MB-231 cells were seeded at a density of $5 \times 10^{4}$ cells/well and treated with vehicle (DMSO), doxorubicin (125 nM), RIDR-PI-103 (10 $\mu$ M) and indicated combination in serum free media for $24 \mathrm{~h}$. (B) MDA-MB-361 cells were seeded at the same density and treated with indicated combination in serum free media for $24 \mathrm{~h}$. (C) MDA-MB-453 cells were seeded at a density of $5 \times 10^{4}$ cells/well and treated with vehicle (DMSO), doxorubicin (125 nM), RIDR-PI-103 $(10 \mu \mathrm{M})$ and indicated combination in serum free media for 48 h. $10 \%$ FBS was added as a chemoattractant in the lower chamber. After $24-48 \mathrm{~h}$, the migrated cells were stained and intensities were measured using ImageJ and expressed as \% of control (panel I). The bar graphs are represented as mean; Error bars: SEM ( $n=3$ independent experiments performed in triplicate), $p$-value $<0.05$ for comparison of * to DMSO, $* *$ for comparison of doxorubicin vs. doxorubicin and RIDR-PI-103, \# for comparison of RIDR-PI-103 vs. doxorubicin and RIDR-PI-103 (panel II).

2.6. The Combination of Doxorubicin and RIDR-PI-103 Results in Enhanced Inhibition of PI3K Signaling and Activates DNA Damage Response

We sought to examine RIDR-PI-103 activity via a series of western blots as shown in Figure 6. RIDR-PI-103 targets PI3K and the downstream AKT signaling pathway. There was no effect of either doxorubicin or RIDR-PI-103 in phosphorylation of AKT at Thr308 (data not shown). In MDA-MB-231 breast cancer cells, a combination of doxorubicin with RIDRPI-103 suppressed AKTSer473 phosphorylation as compared to single agent doxorubicin or RIDR-PI-103 (Figure 6). Doxorubicin leads to DNA damage. The protein p53 is an imperative tumor suppressor molecule which plays an important role in DNA damage signaling and various genomic alterations [28]. Activation of p53 leads to cell cycle arrest or apoptosis. DNA damage induces phosphorylation of p53 at Ser15 and Ser20 and leads to a reduced interaction between p53 and its negative regulator, the oncoprotein MDM2 [29,30]. Our data indicated that doxorubicin (125 nM) in combination with RIDR-PI-103 $(10 \mu \mathrm{M})$ induced p53 phosphorylation at Ser15 in MDA-MB-231 breast cancer cell lines with similar results in MDA-MB-361 and MDA-MB-453 cells. However, we didn't observe p53 posttranslational modification activation in vehicle (DMSO) or doxorubicin treatment alone. We further examined the effect of the combination on cell cycle arrest. CHK1 kinase is 
downstream of ATM/ATR kinase pathway and plays a crucial role in DNA damage checkpoint control and tumor suppression. Doxorubicin in combination with RIDR-PI-103 induced p-CHK1 compared to either single agent. Checkpoint kinase 2 protein, (CHK2) is also downstream of ATM/ATR. CHK2 contain a series of seven serine/threonine residues (Ser19, Thr26, Ser28, Ser33, Ser35, Ser50, and Thr68) each followed by glutamine (SQ or TQ motif) [31]. Examining the phosphorylation of Thr68 of CHK2, our results indicate that doxorubicin, RIDR-PI-103, and the combination increased phosphorylation of CHK2 at T68 most notably in MDA-MB-361 and MDA-MB-453 versus vehicle control. All original images from western blots are included in Figures S5-S13.

A MDA-MB-231

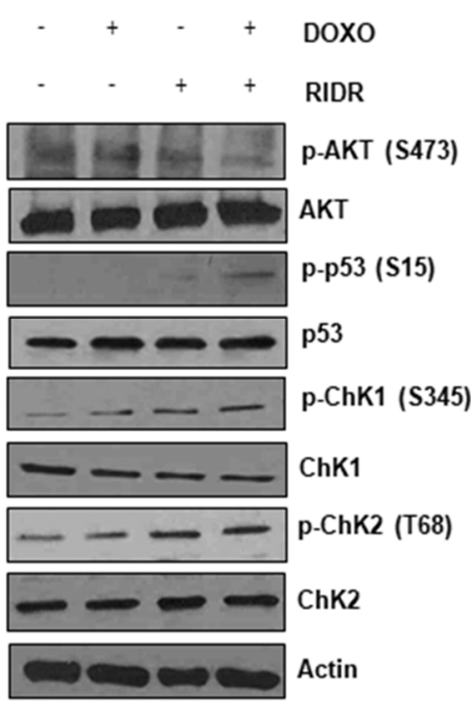

B MDA-MB-361

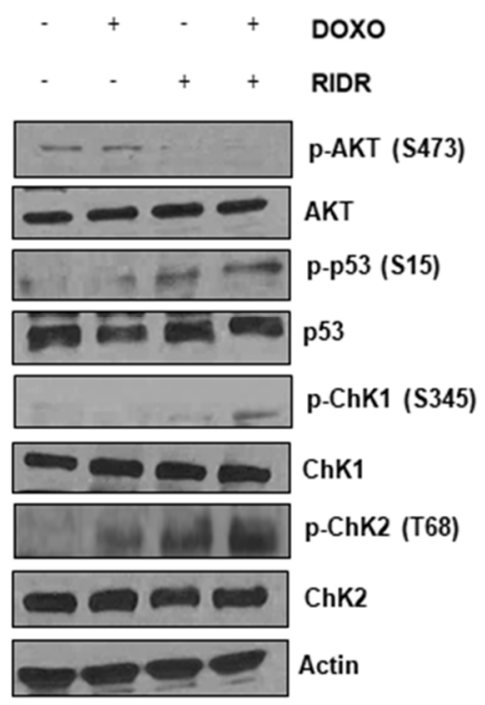

C MDA-MB-453

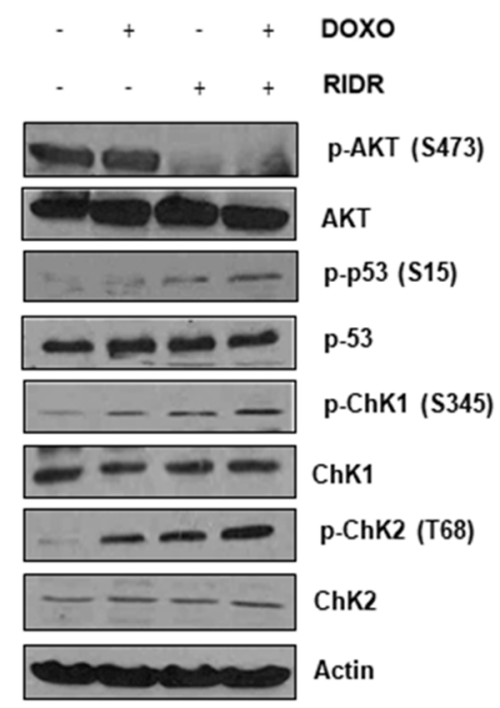

Figure 6. Doxorubicin in combination RIDR-PI-103 inhibits AKT and downstream signaling. Equal number of MDA-MB-231 (A), MDA-MB-361 (B) and MDA-MB-453 (C) cells were treated with vehicle (DMSO), RIDR-PI-103 (10 $\mu$ M), doxorubicin $(125 \mathrm{nM})$ and combination of both for $24 \mathrm{~h}$ and cell lysates were collected and immunoblotted using p-AKTSer473, AKT, p-P53Ser15, P53, p-CHK1S345, CHK1, p-CHK2T68 and CHK2 antibodies. Actin served as loading control.

\subsection{Pharmacokinetics Profile of RIDR-PI-103}

In this initial PK study in mice, RIDR-PI-103 $(20 \mathrm{mg} / \mathrm{kg})$ was administered intraperitoneally and blood samples were collected over a period of $96 \mathrm{~h}$. The concentration of $20 \mathrm{mg} / \mathrm{kg}$ was chosen based on the ability to solubilize RIDR-PI-103 in $40 \%$ propylene glycol with $60 \%$ injectable saline. The mean plasma concentration-time profile was then analyzed using Phoenix ${ }^{\circledR}$ WinNonlin ${ }^{\circledR}$ v8.2 using both a compartmental and noncompartmental analysis (NCA). As shown (Figure 7A,B), the plasma concentration-time profile fitted a one-compartment model. The key PK parameters are listed in Table 1. As shown, both methods of PK analysis yielded similar results. RIDR-PI-103 has a maximal plasma concentration $\left(C_{\max }\right)$ of $201.5 \mathrm{ng} / \mathrm{mL}(0.43 \mu \mathrm{M})$, which was achieved at the time taken to reach the maximum concentration $\left(\mathrm{T}_{\max }\right)$ of $1.44 \mathrm{~h}$. The elimination half-life of RIDR-PI-103 was $9.4 \mathrm{~h}$ (Table 2), aligning with the blood sample schedule employed (up to $96 \mathrm{~h}$, approximately a period equivalent to 10 half-lives) facilitating complete characterization of the elimination profile. Based on these studies, RIDR-PI-103 has a large volume of distribution $(\mathrm{Vd}), 89 \mathrm{~L} / \mathrm{kg}$. 


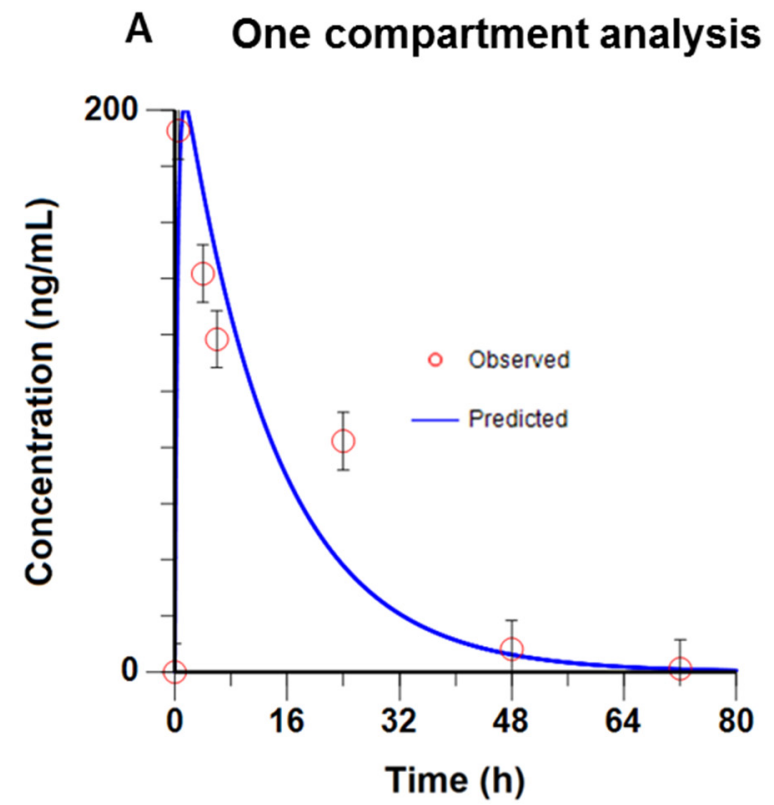

\section{B Non-compartment analysis}

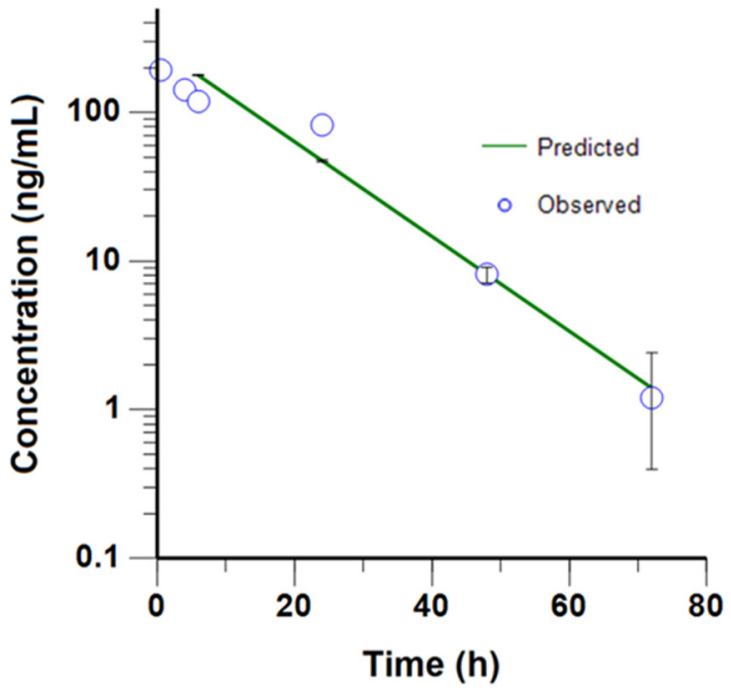

Figure 7. Pharmacokinetic profile of RIDR-PI-103 (A,B). A single dose of RIDR-PI-103 (20 mg/kg) was administered intraperitoneally in mice and serial blood samples were collected over a period of $96 \mathrm{~h}$ ( $n=3$ per time point). Concentrationtime profile for RIDR-PI-103 in mice plasma using one-compartmental and non-compartmental analysis.

Table 1. The key PK parameters for the plasma concentration-time profile fitted a one-compartment model for RIDR-PI-103.

\begin{tabular}{cc}
\hline PK Parameters & Observed Values \\
\hline $\mathrm{V} / \mathrm{F}$ & $89 \mathrm{~L} / \mathrm{kg}$ \\
$\mathrm{K} 01$ & $2.5 \mathrm{~h}^{-1}$ \\
$\mathrm{~K} 10$ & $0.075 \mathrm{~h}^{-1}$ \\
$\mathrm{AUC}(0-72 \mathrm{~h})$ & $2979.8 \mathrm{~h} \cdot \mathrm{ng} / \mathrm{mL}$ \\
Elimination $\mathrm{T}_{1 / 2}$ & $9.18 \mathrm{~h}$ \\
$\mathrm{Cl} / \mathrm{F}$ & $6.7 \mathrm{~L} / \mathrm{h} / \mathrm{kg}$ \\
$\mathrm{T}_{\max }$ & $1.44 \mathrm{~h}$ \\
$\mathrm{C}_{\max }$ & $201.5 \mathrm{ng} / \mathrm{mL}$ \\
\hline
\end{tabular}

Table 2. The key PK parameters for the plasma concentration-time profile fitted a non-compartment model for RIDR-PI-103.

\begin{tabular}{cc}
\hline PK Parameters & Observed Values \\
\hline $\mathrm{V} / \mathrm{F}$ & $89 \mathrm{~L} / \mathrm{kg}$ \\
$\lambda \mathrm{z}$ & $0.073 \mathrm{~h}^{-1}$ \\
$\mathrm{~K} 10$ & $0.073 \mathrm{~h}^{-1}$ \\
$\mathrm{AUC}(0-72 \mathrm{~h})$ & $3897.1 \mathrm{~h} \cdot \mathrm{ng} / \mathrm{mL}$ \\
Elimination $\mathrm{T}_{1 / 2}$ & $9.44 \mathrm{~h}$ \\
$\mathrm{Cl} / \mathrm{F}$ & $5.1 \mathrm{~L} / \mathrm{h} / \mathrm{kg}$ \\
$\mathrm{T}_{\max }$ & $0.5 \mathrm{~h}$ \\
$\mathrm{C}_{\max }$ & $192.8 \mathrm{ng} / \mathrm{mL}$ \\
\hline
\end{tabular}

\section{Discussion}

The PI3K/AKT/mTOR pathway is an important therapeutic target for treatment of breast cancer [2,32]. Several PI3K inhibitors are approved by the FDA for different cancers: Alpelisib in HR+ and HER2/neu negative breast cancer [11], idelalisib for leukemia [33] and two types of lymphoma [34,35], duvelisib for chronic lymphocytic leukemia/small lymphocytic lymphoma [36]. Several other PI3K inhibitors are also in different stages of 
clinical development [37-40]. Drugs targeting PI3K or mTOR catalytic activity are toxic, due to the physiological roles of PI3K/mTOR signaling in basic cellular processes in tissues throughout the body, including protein translation, intracellular trafficking, autophagy, and metabolism. Toxicity that occurs in patients includes hyperglycemia as genes encoding most glycolytic enzymes are under transcriptional control by PI3K/AKT [7].We designed a novel PI-103 prodrug (RIDR-PI-103) such that the PI3K inhibitor PI-103 would only be released under high oxidative stress conditions found in the tumor milieu. Thus, RIDR-PI103 is designed to only inhibit PI3K in the tumor microenvironment under high oxidative stress conditions. This would circumvent the toxicity observed with global inhibition of PI3K throughout the body using current PI3K inhibitors. The study herein describes the efficacy of RIDR-PI-103 in breast cancer cells along with initial PK profile in a mouse model.

Enhanced ROS in non-transformed cells or breast cancer cells could have pro-tumorigenic effects via damaging nucleic acids and inducing genomic instability. Breast cancer subtypes demonstrate differential ROS production and susceptibility to antioxidant treatment. TNBC cells have increased ROS levels compared to non-tumorigenic or ER+/luminal breast cancer cells. TNBCs have higher oxidation states marked with enhanced ROS marker (dihydroethidium and MitoSox) staining compared to ER+ and non-tumorigenic control [26]. This is consistent with our findings demonstrating that TNBC MDA-MB-231 cells have high ROS compared to non-tumorigenic MCF10A cells. Doxorubicin produces ROS in vivo. Further, ROS plays a mechanistic role in the cardiotoxicity induced by doxorubicin involved in breast cancer treatment [41,42]. We found that doxorubicin at a concentration $125 \mathrm{nM}$ induced ROS in breast cancer cell lines (MDA-MB-231, MDA-MB-361 and MDA-MB-453) which was higher than that induced in MCF10A cells (Figure 2A).

The PI3K pathway is significant in maintaining genomic stability by involving DNA replication and cell cycle regulation [43]. For example mTOR inhibition, downstream of PI3K, has been shown to activate p-CHK2 T68, an indicator of ATM-CHK2 checkpoint activation [44]. We examined the effect of combination doxorubicin and RIDR-PI-103 in Akt and DNA damage response signaling. Our data showed that the combination of doxorubicin and RIDR-PI-103 activated p-53 in three cancer cell lines. We observed that doxorubicin and RIDR-PI-103 combined upregulated p-CHK1S345 and p-CHK2T68 in MDA-MB-361 and MDA-MB-453 cells. PI3K inhibition can induce DNA damage via nucleoside depletion notably in cells with genetic aberrations in p53 and BRCA1 [45]. MDA-MB-453 cells have been reported to have a mutation in exon 11 of p53. MDA-MB-231 cells contains a R280K p53 mutation and MDA-MB-361 cells contains a p53 mutation in exon 4 [46]. Thus, inhibition of PI3K with RIDR-PI-103 in these breast cancers could reduce nucleotide triphosphates, resulting in DNA damage and activation of DNA damage response. The exact mechanism(s) by which RIDR-PI-103 can activate a DNA damage response as indicated by increased p-p53, p-CHK1 and p-CHK2 remain to be explored in future studies.

Recently, a bioisostere of PI-103 has been developed with a structural modification containing a boronate in place of a phenolic hydroxyl group with the goal to enhance bioavailability [47]. The boron-containing PI-103 bioisostere demonstrated improved bioavailability relative to PI-103. RIDR-PI-103 differs from the boron-containing compound in that RIDRPI-103 is designed to only release PI-103 under controlled oxidative stress conditions when ROS levels are high, present in the tumor microenvironment milieu. Our goal with the design of RIDR-PI-103 is to circumvent toxicity observed with systemic inhibition of PI3K signaling throughout the body [48].

Herein, we performed an initial PK study meant to estimate some of the drug disposition parameters such as the peak plasma levels, elimination half-life, apparent volume of distributions and total clearance. Since we have not performed a PK study following an intravenous (i.v.) administration, the bioavailability following the intraperitoneal (i.p.) administration cannot be ascertained at this point. The peak plasma concentration at a dose of $20 \mathrm{mg} / \mathrm{kg}$ was $0.43 \mu \mathrm{M}$. The apparent volume of distribution $(89 \mathrm{~L})$ is suggestive of extensive drug distribution while the half-life of approximately $10 \mathrm{~h}$ suggesting that the 
systemic drug elimination is relatively slow. Thus, these derived PK data imply that an efficacious dosing regimen can be developed to yield effective tissue-specific drug levels.

Our study has limitations. The scope of the study focuses on in vitro studies with one in vivo pharmacokinetic study. The PK study was performed in tumor-free mice. In follow up studies, we will first derive a correlation between extracellular (cell culture media) and intracellular concentrations of RIDR-PI-103 which will then reflect on tumor-tissue specific concentrations needed for efficacy in animal models. The PK data derived here can then be employed for designing effective dosing regimen (dose and dosing frequency) by simulating PK profiles assuming linear PK (i.e., no change in the half-life, clearance and volume of distribution). Additional PK studies will measure the amount of PI-103 present, as it will be important to assess the conversion of pro-drug to biologically active drug. Future PK studies will employ a higher dose of RIDR-PI-103 with the initial dose described here using only $20 \mathrm{mg} / \mathrm{kg}$ RIDR-PI-103.

Future studies will examine the in vivo efficacy of single-agent RIDR-PI-103 compared to parent drug PI-103 in breast tumor models. There is evidence that inhibition of PI3Ky protects from anthracycline toxicity [49]. Additional in vivo efficacy studies will examine if RIDR-PI-103 has a cardioprotective effect in combination with doxorubicin as PI-103 is a pan-PI3K inhibitor with an IC50 against PI3Ky of $15 \mathrm{nM}$ [50]. Overall, these results are promising and further help in PK modeling and deduction of a safe and efficacious starting dose for efficacy studies utilizing novel RIDR-PI-103 in breast cancer model.

\section{Materials and Methods}

\subsection{Cell Culture and Inhibitors}

Human breast cancer cells (MDA-MB-231, MDA-MB-361 and MDA-MB-453) were obtained from American Type Culture Collection (ATCC). MCF10A cells were a generous gift from Dr. Nalinikanth Kotagiri, College of Pharmacy, University of Cincinnati. NHfibroblast was obtained from Dr. Edward J. Merino, Department of Chemistry, University of Cincinnati. MDA-MB-231 cells were maintained in RPMI media supplemented with 10\% Fetal Bovine Serum (FBS). MDA-MB-361, MCF10A and MDA-MB-453 cells were cultured in DMEM media with $10 \%$ FBS. NH-fibroblasts cells were maintained in MDME media with $10 \%$ FBS and supplemented with growth factors such as insulin, hydrocortisone and epidermal growth factor (EGF). RIDR-PI-103 was synthesized in collaboration with Dr. Edward J. Merino [20]. Doxorubicin (Cat\# D-4000) and docetaxel (Cat\# D-1000) were obtained from LC Laboratories (Woburn, MA, USA). All these compounds were prepared in DMSO solvent.

\subsection{Immunoblot Analysis}

Cells were lysed in RIPA buffer (Thermo Fisher Scientific, Waltham, MA, USA, Cat\#BP115) supplemented with protease and phosphatase inhibitors (Thermo Fisher Scientific, Cat\#88669). Immunoblotting was performed using the following antibodies: p-AktS473 (Cell Signaling Technology, Danvers, MA, USA Cat\#4060), Akt (Cell Signaling Technology, Cat\#9272), p-P53S15 (Cell Signaling Technology, Cat\#9286), P53 (Cell Signaling Technology, Cat\#2527), p-CHK1S345 (Cell Signaling Technology, Cat\#2348), CHK1 (Cell Signaling Technology, Cat\#2360), p-CHK2T68 (Cell Signaling Technology, Cat\#2661), CHK2 (Cell Signaling Technology, Cat\#6334), and Actin (Santa Cruz Biotechnology, Dallas, TX, USA, Cat\# SC-1616). Peroxidase-conjugated secondary antibodies (Santa Cruz Biotechnology) were used and protein signals were detected using Pierce ECL western blotting substrate (Thermo Fisher Scientific, Cat\# 32106).

\subsection{Cell Viability Assay}

Growth kinetics of fibroblasts, MCF10A, MDA-MB-231, MDA-MB-361 and MDA-MB453 cells was determined by the 4,5-dimethylthiazol-2-yl)-2,5-diphenyltetrazolium bromide (MTT) assay. Briefly, $2 \times 10^{4}$ cells/well were seeded in 96 well plates in triplicate. After $72 \mathrm{~h}$ of treatment with RIDR-PI-103 $(0-110 \mu \mathrm{M})$ and PI-103 $(0-5 \mu \mathrm{M})$, media was substituted 
with $50 \mathrm{mg} / \mathrm{mL}$ MTT solution (Sigma Aldrich, St. Louis, MO, USA) and absorbance was recorded at $570 \mathrm{~nm}$ using SPECTRAmax PLUS Microplate Spectrophotometer Plate Reader (Molecular Devices Corporation, San Jose, CA, USA) and expressed as the mean of triplicates relative to vehicle (DMSO) control together with standard error of mean (SEM). In separate experiments, MDA-MB-231, MDA-MB-361 and MDA-MB-453 cells were treated with a series of concentrations using doxorubicin in the presence or absence of RIDR-PI-103 (10-30 $\mu \mathrm{M})$. MDA-MB-231 cells were treated with 500-5000 nM, MDA-MB-361 with 50-450 nM and MDA-MB-453 with 100-4000 nM of doxorubicin for $72 \mathrm{~h}$. MDA-MB231, MDA-MB-361 and MDA-MB-453 cells were treated with a series of concentrations using docetaxel in the presence or absence of RIDR-PI-103 (10, 15 or $30 \mu \mathrm{M})$. MDA-MB-231 cells were treated with 50-50,000 pM docetaxel. MDA-MB-361 cells were treated with 10-90 $\mathrm{nM}$ of docetaxel. MDA-MB-453 cells were subjected 50-10,000 pM of docetaxel. The cell proliferation was analyzed after $72 \mathrm{~h}$ and represented as mean of triplicate values relative to DMSO control. The bar graph generated using graph pad prism 7 (GraphPad Software, Inc., La Jolla, CA, USA).

\subsection{Cell Proliferation Assay}

MDA-MB-231, MDA-MB-361 and MDA-MB-453 cells were seeded at a density of $5 \times 10^{4}$ cells/well in 6 well plates (Thermo Fisher Scientific) in triplicate. Complete media containing $125 \mathrm{nM}$ doxorubicin or $10 \mu \mathrm{M}$ RIDR-PI-103 alone or combination of both respectively was replaced every alternate day and cells were stained with $0.5 \%$ crystal violet in methanol within 7-10 days. The intensities were measured using an Odyssey infrared system (LI-COR, Lincoln, NE, USA). The values are expressed as mean of intensities obtained from 3 independent experiments.

\subsection{Cell Migration Assay}

MDA-MB-231, MDA-MB-361 and MDA-MB-453 cells were seeded at a density of $5 \times 10^{4}$ cells / well in 6 well plates and treated with vehicle (DMSO), $125 \mathrm{nM}$ doxorubicin and $10 \mu \mathrm{M}$ RIDR-PI-103 or combination of both for $8 \mathrm{~h}$. After $8 \mathrm{~h}$, cells were counted and $2 \times 10^{4}$ cells/well were added to the upper chamber of transwell and incubated for $24-48 \mathrm{~h}$. After $24-48$ h, migrated cells in the lower chamber were stained with $0.5 \%$ crystal violet and images were captured from three areas under phase contrast microscope. The intensities from three areas collected from three independent experiments were measured using ImageJ and expressed as \% of control and represented graphically.

\subsection{Measurement of Intracellular ROS}

MCF10A, MDA-MB-231, MDA-MB-361 and MDA-MB-453 cells $\left(2 \times 10^{4}\right)$ were plated and treated with or without $125 \mathrm{nM}$ of doxorubicin for $30 \mathrm{~min}$ at $37^{\circ} \mathrm{C}$. The cells were resuspended in dichlorodihydrofluorescein diacetate (DCFH-DA) for $30 \mathrm{~min}$ at analyzed using the CellQuest software v4.0.1 (Becton Dickinson and Company, Franklin Lakes, NJ, USA) to measure the ROS levels. The DCFH-DA levels were measured using a SPECTRAmax PLUS Microplate Spectrophotometer Plate Reader (Molecular Devices Corporation).

\subsection{Matrigel Colony Formation}

Three-dimensional (3D) growth assays were performed in growth factor-reduced matrigel (BD Biosciences, San Jose, CA, USA) where 96 well plates were coated with $80 \mu \mathrm{L}$ of matrigel/well. MDA-MB-231, MDA-MB-361 and MDA-MB-453 cells $\left(1 \times 10^{4} /\right.$ well $)$ were plated and incubated at $37^{\circ} \mathrm{C}$ for $24 \mathrm{~h}$. Cells were treated with vehicle (DMSO), $10 \mu \mathrm{M}$ RIDRPI-103 or $125 \mathrm{nM}$ doxorubicin or combination of both every alternate day. After 10 days of incubation, colonies were visualized and photographs were captured from 3 random fields under microscope (Nikon, Road Melville, NY, USA) at $10 \times$ magnification. The areas of the colonies were measured by ImageJ and represented as mean areas normalized to DMSO control. The experiments were repeated 3 times to confirm the results. 


\subsection{Analytical Methods}

A high performance liquid chromatography (HPLC) was used to analyze serial dilutions of RIDR-PI-103 (1000, 500, 250, 125, $12.5 \mathrm{ng} / \mathrm{mL})$ as described previously [28]. Briefly, we employed a Waters column (Milford, MA, USA) and the samples were eluted using mobile phases A: $95 \%$ water $+5 \%$ acetonitrile and B: $5 \%$ water $+95 \%$ acetonitrile. The HPLC was performed using a gradient method, with $0 \%$ B for $4 \mathrm{~min}$ and $95 \%$ B for over $15 \mathrm{~min}$. The flow was $1 \mathrm{~mL} / \mathrm{min}$. A detection wavelength of $250 \mathrm{~nm}$ was used on Waters 2487 Dual Wavelength Absorbance Detector. Once the HPLC method was developed, we then set up a liquid-liquid extraction method for RIDR-PI-103 from mouse plasma. Extractions were performed using standard liquid-liquid extraction process with methyl tert-butyl ether (MTBE) used as extraction solvent. The samples were reconstituted in $100 \mu \mathrm{L}$ of PBS: DMSO $(99: 1 v / v)$ and the $\mathrm{pH}$ was adjusted to 2 using $1 \mathrm{M}$ hydrochloric acid $(\mathrm{HCl})$. The extraction efficiency was observed to be $\sim 40 \%$ with the limit of detection between $1.25 \mathrm{ng} / \mathrm{mL}$ and $1250 \mathrm{ng} / \mathrm{mL}$.

\subsection{Pharmacokinetic Analysis}

The plasma concentration-time profile of RIDR-PI-103 was analyzed using Phoenix ${ }^{\circledR}$ WinNonlin ${ }^{\circledR}$ v8.2 (Certara L.P. (Pharsight), St. Louis, MO, USA). Regression analysis of the data suggested that a compartment model best fitted the data. This was based on observed goodness of fit (random distribution of the residual around the predicted curve) and the Akaike Information Criterion (AIC), and the Schwarz Criterion (SC). The important PK parameters derived using this approach included elimination half-life $\left(\mathrm{T}_{\frac{1}{2}}\right)$, time required to achieve peak plasma concentrations $\left(\mathrm{T}_{\max }\right)$, total Area Under the concentration-time Curve (AUC0- $\infty$ ) and systemic oral clearance $(\mathrm{CL} / \mathrm{F})$ and apparent volume of distribution $(\mathrm{Vd} / \mathrm{F})$. " $\mathrm{F}$ " is the bioavailability following the intraperitoneal (i.p) administration and cannot be estimated in the absence of intravenous (i.v.) administration. We also employed the non-compartmental analysis (NCA) to verify the PK parameters derived using the one-compartment model. The NCA utilizes the trapezoidal rule for AUC (0-tlast) determination over the blood sample collection period. The regression analysis of the last four concentration-time values $(24,48,72$ and $96 \mathrm{~h})$ was done to determine the elimination rate constant (Kel). PK parameters such as AUC $(0-\infty), \mathrm{Cl} / \mathrm{F}, \mathrm{Vd} / \mathrm{F}$ and the elimination half-life were then computed as shown below:

$$
\begin{gathered}
\text { AUC }(0-\infty)=\operatorname{AUC}(0-\text { tlast })+\text { Clast } / \text { kel } \\
\mathrm{Cl} / \mathrm{F}=\text { Dose } / \mathrm{AUC}(0-\infty) \\
\mathrm{Vd} / \mathrm{F}=(\mathrm{Cl} / \mathrm{F}) / \text { kel }
\end{gathered}
$$

\subsection{Animal Studies}

Female C57BL/6J mice at 4 weeks were used with $n=3$ per time point. Time points for blood collection were based on previous findings regarding the in vitro microsomal metabolic stability of RIDR-PI-103 [20]. RIDR-PI-103 was formulated using a mixture of $40 \%$ propylene glycol with $60 \%$ injectable saline in which RIDR-PI-103 was soluble in solution and not a suspension. The stability of RIDR-PI-103 in this formulation was ascertained by measuring drug content over 7 days. RIDR-PI-103 (dose $=20 \mathrm{mg} / \mathrm{kg}$ ) was injected intraperitoneally in all mice at the start of the experiment. Blood collection was done via cardiac puncture under anesthesia at $0,0.5,4,6,24,48,72,96 \mathrm{~h}$ post injection. Plasma was isolated from the blood samples by centrifugation and was stored at $-80^{\circ} \mathrm{C}$ until further analysis. Institutional Animal Care and Use Committee (IACUC), University of Cincinnati ethically approved the in vivo mouse experiment under protocol AM02-1908-28-01, approved on 27 July 2020. 


\subsection{1. qPCR Analysis of Antioxidant mRNAs}

Total RNA was extracted from fibroblasts, MDA-MB-231, MDA-MB-361 and MDAMB-453 cells using the RNA extraction mini kit (Qiagen, Germantown, MD, USA) according to the manufacturer's instruction. Two-step RT-qPCR was performed to assess the mRNA level of SOD1, SOD2, CAT, PRDX1 and GSR. First strand cDNA was synthesized using iScriptTM cDNA Synthesis Kit (BioRad, Hercules, CA, USA). q-PCR was set up using CFX96 Real-Time System (BioRad). Actin was used as an internal control. Paired primer sequences used were SOD1: 5'-GGTGGGCCAAGGATGAAGAG-3' (forward) and 5'CCACAAGCCAACGACTTCC-3' (reverse); SOD2: $5^{\prime}$-GCTCCGGTTTTGGGGTATCTG-3' (forward) and $5^{\prime}$-GCGTTGATGTGAGGTTCCAG-3' (reverse); CAT 5' -TGGAGCTGGTAAC CCAGTAGG-3' (forward) and $5^{\prime}$-CCTTTGCCTTGGAGTATTTGGTA-3' (reverse); PRDX1 $5^{\prime}$ - CCACGGAGATCATTGCTTTCA-3' (forward) and 5'-AGGTGTATTGACCCATGCTAGA T - $3^{\prime}$ (reverse); GSR: 5'-CACTTGCGTGAATGTTGGATG-3' (forward) and 5'-TGGGATCAC TCGTGAAGGCT-3' (reverse); and Actin: 5'AAGGAGCCCCACGAGAAAAAT-3' (forward); 5' - ACCGAACTTGCATTGATTCCAG-3'.

\subsection{Statistical Analysis}

Data are shown as the mean \pm standard error of mean (SEM) and representative of at least three independent experiments unless otherwise indicated. Statistical analysis among groups using the two-tailed Student's $t$-test, one-way analysis of variance, $p<0.05$ was considered statistically significant.

\section{Conclusions}

We describe a ROS-activated prodrug (RIDR-PI-103) that in combination with doxorubicin inhibits breast tumor growth and migration. Our data indicated that doxorubicin with RIDR-PI-103 downregulated Akt signaling and activated DNA damage response signals.

Supplementary Materials: The following are available online at https:/ / www.mdpi.com/1422-0 067/22/4/2088/s1, Figure S1: Dose response of PI-103 in MCF10A, normal fibroblasts and breast cancer cells, Figure S2: Endogenous antioxidants levels in fibroblast and breast cancer cell lines, Figure S3: NAC, a ROS scavenger rescues the antiproliferative effects of combination RIDR-PI-103 and doxorubicin in MDA-MB-231 but not MDA-MB-453 cells. Figure S4: Docetaxel did not sensitize RIDR-PI-103 in breast cancer cells, Figure S5: Whole blot image of p-AKT/AKT/Actin in MDA-MB231 cells from Figure 6A, Figure S6. Whole blot image of p-CHK1S345/CHK1 and p-CHK2T68/CHK2 in MDA-MB-231 cells from Figure 6A, Figure S7. Whole blot image of p-p53 and p53 in MDA-MB-231 cells from Figure 6A, Figure S8: Whole blot image of p-AKT/AKT/Actin in MDA-MB-361 cells from Figure 6B, Figure S9. Whole blot image of p-p53 and p53 in MDA-MB-361 cells from Figure 6B, Figure S10. Whole blot image of p-CHK1S345/CHK1 and p-CHK2T68/CHK2 in MDA-MB-361 cells from Figure 6B, Figure S11. Whole blot image of p-AKT/AKT/Actin in MDA-MB-453 cells from Figure 6C, Figure S12. Whole blot image of p-p53 and p53 in MDA-MB-453 cells from Figure 6C, Figure S13. Whole blot image of p-CHK1S345/CHK1 and p-CHK2T68/CHK2 in MDA-MB-453 cells from Figure 6C. Table S1: Comparison of IC50 values of RIDR-PI-103 vs. PI-103. Table S2: IC50 values of DOXO, DOXO $\pm 10 \mu \mathrm{M}$ RIDR, DOXO $\pm 15 \mu \mathrm{M}$ RIDR and DOXO $\pm 30 \mu \mathrm{M}$ RIDR in MDA-MB-231, MDA-MB-361 and MDA-MB-453 cell lines.

Author Contributions: Data generation, R.M., L.Y., H.P., A.S.K., A.W.; Methodology, R.M., L.Y. and H.Z.; Project administration, J.T.G. and E.J.M.; Resources, E.J.M.; Writing-original draft, R.M., A.S.K. and J.T.G., Writing \& editing, R.M., P.D., S.A. and J.T.G. All authors have read and agreed to the published version of the manuscript.

Funding: This work was funded by a Collaborative Advancement Grants Program-Strategic Teams, Office of Research, University of Cincinnati (J.T.G., E.J.M.), \#R40309, 5/1/2019 to 4/30/2021.

Institutional Review Board Statement: Not applicable.

Informed Consent Statement: Not applicable.

Data Availability Statement: Not applicable. 
Conflicts of Interest: The authors declare no conflict of interest.

\section{References}

1. Cantley, L.C. The Phosphoinositide 3-Kinase Pathway. Science 2002, 296, 1655-1657. [CrossRef] [PubMed]

2. Baselga, J. Targeting the phosphoinositide-3 (PI3) kinase pathway in breast cancer. Oncology 2011, 16, 12-19. [CrossRef]

3. Zhao, L.; Vogt, P.K. Class I PI3K in oncogenic cellular transformation. Oncogene 2008, 27, 5486-5496. [CrossRef] [PubMed]

4. Miller, T.W.; Balko, J.M.; Arteaga, C.L. Phosphatidylinositol 3-kinase and antiestrogen resistance in breast cancer. J. Clin. Oncol. 2011, 29, 4452-4461. [CrossRef] [PubMed]

5. Miller, T.W.; Rexer, B.N.; Garrett, J.T.; Arteaga, C.L. Mutations in the phosphatidylinositol 3-kinase pathway: Role in tumor progression and therapeutic implications in breast cancer. Breast Cancer Res. 2011, 13, 224. [CrossRef]

6. Lorusso, P.M. Inhibition of the PI3K/AKT/mTOR pathway in solid tumors. J. Clin. Oncol. 2016, 34, 3803-3815. [CrossRef] [PubMed]

7. Nunnery, S.; Mayer, I. Management of toxicity to isoform $\alpha$-specific PI3K inhibitors. Ann. Oncol. 2019, 30, x21-x26. [CrossRef] [PubMed]

8. André, F.; Ciruelos, E.; Rubovszky, G.; Campone, M.; Loibl, S.; Rugo, H.S.; Iwata, H.; Conte, P.; Mayer, I.A.; Kaufman, B.; et al. Alpelisib for PIK3CA-mutated, hormone receptor-positive advanced breast cancer. N. Engl. J. Med. 2019, 380, 1929-1940. [CrossRef]

9. Markham, A. Alpelisib: First global approval. Drugs 2019, 79, 1249-1253. [CrossRef]

10. Kumari, S.; Badana, A.K.; Murali Mohan, G.; Shailender, G.; Malla, R.R. Reactive oxygen species: A key constituent in cancer survival. Biomark. Insights 2018, 13, 1-9. [CrossRef]

11. Johar, R.; Sharma, R.; Kaur, A.; Mukherjee, T.K. Role of reactive oxygen species in estrogen dependant breast cancer complication. Anti-Cancer Agents Med. Chem. 2015, 16, 190-199. [CrossRef] [PubMed]

12. Fortin, J.; Mak, T.W. Targeting PI3K Signaling in cancer: A cautionary tale of two AKTs. Cancer Cell 2016, 29, 429-431. [CrossRef] [PubMed]

13. Fruman, D.A.; Chiu, H.; Hopkins, B.D.; Bagrodia, S.; Cantley, L.C.; Abraham, R.T. The PI3K pathway in human disease. Cell 2017, 170, 605-635. [CrossRef]

14. Thorpe, L.M.; Yuzugullu, H.; Zhao, J.J. PI3K in cancer: Divergent roles of isoforms, modes of activation and therapeutic targeting. Nat. Rev. Cancer 2015, 15, 7-24. [CrossRef]

15. Shen, S.; He, X.; Yang, Z.; Zhang, L.; Liu, Y.; Zhang, Z.; Wang, W.; Liu, W.; Li, Y.; Huang, D.; et al. Discovery of an orally bioavailable dual PI3K/mTOR inhibitor based on sulfonyl-substituted morpholinopyrimidines. ACS Med. Chem. Lett. 2018, 9 , 719-724. [CrossRef]

16. Yu, T.; Li, N.; Wu, C.; Guan, A.; Li, Y.; Peng, Z.; He, M.; Li, J.; Gong, Z.; Huang, L.; et al. Discovery of pyridopyrimidinones as potent and orally active dual inhibitors of PI3K/mTOR. ACS Med. Chem. Lett. 2018, 9, 256-261. [CrossRef]

17. Raynaud, F.I.; Eccles, S.; Clarke, P.A.; Hayes, A.; Nutley, B.; Alix, S.; Henley, A.; Di-Stefano, F.; Ahmad, Z.; Guillard, S.; et al. Pharmacologic characterization of a potent inhibitor of class I phosphatidylinositide 3-kinases. Cancer Res. 2007, 67, 5840-5850 [CrossRef]

18. Enzenmüller, S.; Gonzalez, P.; Debatin, K.-M.; Fulda, S. Chloroquine overcomes resistance of lung carcinoma cells to the dual PI3K/mTOR inhibitor PI103 by lysosome-mediated apoptosis. Anti-Cancer Drugs 2013, 24, 14-19. [CrossRef] [PubMed]

19. Li, D.; Zou, Z.-Q.; Zhang, X.-H.; Wang, F.; Shen, Q.-J.; Xu, J.; Zhang, L.-N.; Xing, W.-H.; Zhuo, R.-J. A novel dual PI3K $\alpha / m$ TOR inhibitor PI-103 with high antitumor activity in non-small cell lung cancer cells. Int. J. Mol. Med. 2009, 24, 97-101. [CrossRef] [PubMed]

20. Zhu, H.; Mishra, R.; Yuan, L.; Salam, S.F.A.; Liu, J.; Gray, G.; Sterling, A.D.; Wunderlich, M.; Landero-Figueroa, J.; Garrett, J.T.; et al. Oxidative cyclization-induced activation of a phosphoinositide 3-kinase inhibitor for enhanced selectivity of cancer chemotherapeutics. ChemMedChem 2019, 14, 1933-1939. [CrossRef] [PubMed]

21. McGowan, J.V.; Chung, R.; Maulik, A.; Piotrowska, I.; Walker, J.M.; Yellon, D.M. Anthracycline Chemotherapy and Cardiotoxicity. Cardiovasc. Drugs Ther. 2017, 31, 63-75. [CrossRef]

22. Kim, S.-Y.; Kim, S.-J.; Kim, B.-J.; Rah, S.-Y.; Chung, S.M.; Im, M.-J.; Kim, U.-H. Doxorubicin-induced reactive oxygen species generation and intracellular $\mathrm{Ca}^{+}{ }^{+}$increase are reciprocally modulated in rat cardiomyocytes. Exp. Mol. Med. 2006, 38, 535-545. [CrossRef]

23. Asensio-López, M.C.; Soler, F.; Pascual-Figal, D.; Fernández-Belda, F.; Lax, A. Doxorubicin-induced oxidative stress: The protective effect of nicorandil on HL-1 cardiomyocytes. PLOS ONE 2017, 12, e0172803. [CrossRef]

24. Octavia, Y.; Tocchetti, C.G.; Gabrielson, K.L.; Janssens, S.; Crijns, H.J.; Moens, A.L. Doxorubicin-induced cardiomyopathy: From molecular mechanisms to therapeutic strategies. J. Mol. Cell. Cardiol. 2012, 52, 1213-1225. [CrossRef]

25. Barretina, J.; Caponigro, G.; Stransky, N.; Venkatesan, K.; Margolin, A.A.; Kim, S.; Wilson, C.J.; Lehár, J.; Kryukov, G.V.; Sonkin, D.; et al. The Cancer Cell Line Encyclopedia enables predictive modelling of anticancer drug sensitivity. Nature 2012, 483 , 603-607. [CrossRef] 
26. Sarmiento-Salinas, F.L.; Delgado-Magallón, A.; Montes-Alvarado, J.B.; Ramírez-Ramírez, D.; Flores-Alonso, J.C.; Cortés-Hernández, P.; Reyes-Leyva, J.; Herrera-Camacho, I.; Anaya-Ruiz, M.; Pelayo, R.; et al. Breast cancer subtypes present a differential production of reactive oxygen species (ROS) and susceptibility to antioxidant treatment. Front. Oncol. 2019, 9, 480. [CrossRef]

27. Rowinsky, E.K.; Onetto, N.; Canetta, R.M.; Arbuck, S.G. Taxol: The first of the taxanes, an important new class of antitumor agents. Semin. Oncol. 1992, 19, 646-662.

28. Levine, A.J. p53, the Cellular Gatekeeper for Growth and Division. Cell 1997, 88, 323-331. [CrossRef]

29. Tibbetts, R.S.; Brumbaugh, K.M.; Williams, J.M.; Sarkaria, J.N.; Cliby, W.A.; Shieh, S.-Y.; Taya, Y.; Prives, C.; Abraham, R.T. A role for ATR in the DNA damage-induced phosphorylation of p53. Genes Dev. 1999, 13, 152-157. [CrossRef]

30. Shieh, S.-Y.; Ikeda, M.; Taya, Y.; Prives, C. DNA Damage-Induced phosphorylation of p53 alleviates inhibition by MDM2. Cell 1997, 91, 325-334. [CrossRef]

31. Matsuoka, S.; Rotman, G.; Ogawa, A.; Shiloh, Y.; Tamai, K.; Elledge, S.J. Ataxia telangiectasia-mutated phosphorylates Chk2 in vivo and in vitro. Proc. Natl. Acad. Sci. USA 2000, 97, 10389-10394. [CrossRef]

32. Verret, B.; Cortes, J.; Bachelot, T.; Andre, F.; Arnedos, M. Efficacy of PI3K inhibitors in advanced breast cancer. Ann. Oncol. 2019, 30, x12-x20. [CrossRef]

33. Brown, J.R.; Byrd, J.C.; Coutre, S.E.; Benson, D.M.; Flinn, I.W.; Wagner-Johnston, N.D.; Spurgeon, S.E.; Kahl, B.S.; Bello, C.; Webb, H.K.; et al. Idelalisib, an inhibitor of phosphatidylinositol 3-kinase p1108, for relapsed/refractory chronic lymphocytic leukemia. Blood 2014, 123, 3390-3397. [CrossRef] [PubMed]

34. Salles, G.; Schuster, S.J.; De Vos, S.; Wagner-Johnston, N.D.; Viardot, A.; Blum, K.A.; Flowers, C.R.; Jurczak, W.J.; Flinn, I.W.; Kahl, B.S.; et al. Efficacy and safety of idelalisib in patients with relapsed, rituximab- and alkylating agent-refractory follicular lymphoma: A subgroup analysis of a phase 2 study. Haematologica 2017, 102, e156-e159. [CrossRef] [PubMed]

35. Cheah, C.Y.; Fowler, N.H. Idelalisib in the management of lymphoma. Blood 2016, 128, 331-336. [CrossRef] [PubMed]

36. Blair, H.A. Duvelisib: First global approval. Drugs 2018, 78, 1847-1853. [CrossRef]

37. Kurtz, J.-E.; Ray-Coquard, I. PI3 kinase inhibitors in the clinic: An update. Anticancer. Res. 2012, 32, $2463-2470$.

38. Janku, F. Phosphoinositide 3-kinase (PI3K) pathway inhibitors in solid tumors: From laboratory to patients. Cancer Treat. Rev. 2017, 59, 93-101. [CrossRef] [PubMed]

39. Zhao, W.; Qiu, Y.; Kong, D. Class I phosphatidylinositol 3-kinase inhibitors for cancer therapy. Acta Pharm. Sin. B 2017, 7, 27-37. [CrossRef]

40. Elmenier, F.M.; Lasheen, D.S.; Abouzid, K.A. Phosphatidylinositol 3 kinase (PI3K) inhibitors as new weapon to combat cancer. Eur. J. Med. Chem. 2019, 183, 111718. [CrossRef]

41. Doroshow, J.H.; Esworthy, R.S.; Chu, F.-F. Control of doxorubicin-induced, reactive oxygen-related apoptosis by glutathione peroxidase 1 in cardiac fibroblasts. Biochem. Biophys. Rep. 2020, 21, 100709. [CrossRef]

42. Cappetta, D.; De Angelis, A.; Sapio, L.; Prezioso, L.; Illiano, M.; Quaini, F.; Rossi, F.; Berrino, L.; Naviglio, S.; Urbanek, K. Oxidative stress and cellular response to doxorubicin: A common factor in the complex milieu of anthracycline cardiotoxicity. Oxidative Med. Cell. Longev. 2017, 2017, 1521020. [CrossRef] [PubMed]

43. Lamm, N.; Rogers, S.; Cesare, A.J. The mTOR pathway: Implications for DNA replication. Prog. Biophys. Mol. Biol. 2019, 147, 17-25. [CrossRef]

44. Zhou, X.; Liu, W.; Hu, X.; Dorrance, A.; Garzon, R.; Houghton, P.J.; Shen, C. Regulation of CHK1 by mTOR contributes to the evasion of DNA damage barrier of cancer cells. Sci. Rep. 2017, 7, 1535. [CrossRef]

45. Juvekar, A.; Hu, H.; Yadegarynia, S.; Lyssiotis, C.A.; Ullas, S.; Lien, E.C.; Bellinger, G.; Son, J.; Hok, R.C.; Seth, P.; et al. Phosphoinositide 3-kinase inhibitors induce DNA damage through nucleoside depletion. Proc. Natl. Acad. Sci. USA 2016, 113, E4338-E4347. [CrossRef]

46. Bouaoun, L.; Sonkin, D.; Ardin, M.; Hollstein, M.; Byrnes, G.; Zavadil, J.; Olivier, M. TP53 variations in human cancers: New lessons from the IARC TP53 database and genomics data. Hum. Mutat. 2016, 37, 865-876. [CrossRef] [PubMed]

47. Luo, L.; Zhong, Q.; Guo, S.; Zhang, C.; Zhang, Q.; Zheng, S.; He, L.; Wang, G. Development of a bioavailable boron-containing PI-103 Bioisostere, PI-103BE. Bioorganic Med. Chem. Lett. 2020, 30, 127258. [CrossRef] [PubMed]

48. Greenwell, I.B.; Ip, A.; Cohen, J.B. PI3K Inhibitors: Understanding toxicity mechanisms and management. Oncology 2017, 31, 821-828.

49. Li, M.; Sala, V.; De Santis, M.C.; Cimino, J.; Cappello, P.; Pianca, N.; Di Bona, A.; Margaria, J.P.; Martini, M.; Lazzarini, E.; et al. Phosphoinositide 3-kinase gamma inhibition protects from anthracycline cardiotoxicity and reduces tumor growth. Circulation 2018, 138, 696-711. [CrossRef]

50. Raynaud, F.I.; Eccles, S.A.; Patel, S.; Alix, S.; Box, G.; Chuckowree, I.; Folkes, A.; Gowan, S.; Brandon, A.D.H.; Di Stefano, F.; et al. Biological properties of potent inhibitors of class I phosphatidylinositide 3-kinases: From PI-103 through PI-540, PI-620 to the oral agent GDC-0941. Mol. Cancer Ther. 2009, 8, 1725-1738. [CrossRef] 